\title{
COMMENT
}

\section{Bird mortality due to the Deepwater Horizon oil spill: Comment on Haney et al. (2014a,b)}

\author{
Brandon S. Sackmann ${ }^{1, *}$, D. Scott Becker ${ }^{2}$ \\ Integral Consulting Inc., ${ }^{1} 1205$ West Bay Drive NW, Olympia, WA 98502, USA, and ${ }^{2} 719$ 2nd Avenue, Suite 700, Seattle, \\ WA 98104, USA
}

\begin{abstract}
Haney et al. (2014a,b; Mar Ecol Prog Ser 513:225-237, 239-252) developed probability models to estimate seabird mortality from oil exposure during the Deepwater Horizon oil spill. Although frequently used to characterize avian mortality following oil spills, probability models often yield uncertain results when developed without spill- and/or region-specific data. Models based on observations of beached carcasses or exposure/mortality scenarios are sensitive to variations in assumptions and methods used to summarize data sets for model parameterization and validation. Here we present alternative parameter estimates derived from spill- and Gulf of Mexico (GoM)-specific data, and offer suggestions for reducing model uncertainty. As a primary example, we evaluate the carcass transport probability to shorelines using GoM-specific data collected in 2011 to show that Haney et al. underestimated this probability by more than an order of magnitude, thus inflating mortality estimates.
\end{abstract}

KEY WORDS: Deepwater Horizon · Avian mortality · Exposure probability · Carcass sampling · Oil spill $\cdot$ Gulf of Mexico $\cdot$ Christmas Bird Count · Marine birds

\section{Introduction}

Haney et al. (2014a,b) developed probability models to estimate mortality of offshore and coastal seabirds ( $>40 \mathrm{~km}$ and $<40 \mathrm{~km}$ from the coast, respectively) due to oil exposure during the Deepwater Horizon oil spill (DHOS). Coastal seabird mortality was estimated using two methods: (1) a carcass sampling probability model, which estimates bird mortality by extrapolating from carcasses recovered during shoreline surveys; (2) an exposure probability model, which estimates bird mortality by combining estimates of density and bird renewal rate with estimates of spill area and proportion of birds dying as a result of oiling.

Although frequently used to characterize avian mortality following oil spills, probability models yield uncertain results when developed without spill- and/or region-specific data (Paine et al. 1996, Camphuysen

\footnotetext{
*Corresponding author: bsackmann@integral-corp.com
}

\& Heubeck 2001, French McCay \& Rowe 2004). Models based on observations of beached carcasses and those based on exposure/mortality scenarios are sensitive to variations in assumptions and methods used to summarize data sets for model parameterization and validation. Many of the estimates of model parameters in Haney et al. are questionable, and uncertainty in the predictions of seabird mortality could be reduced considerably through the use of Gulf of Mexico (GoM)-specific data.

\section{Model parameterization and validation}

Haney et al. $(2014 a, b)$ discussed and appropriately caveated only some of their assumptions. The following list of concerns is not exhaustive, but highlights inherent problems with the data used to parameterize and validate their probability models.

() Integral Consulting Inc. 2015. Open Access under Creative Commons by Attribution Licence. Use, distribution and reproduction are unrestricted. Authors and original publication must be credited.

Publisher: Inter-Research · www.int-res.com 
Lack of GoM- and spill-specific estimates

To accurately estimate parameters of a carcass sampling model and achieve realistic estimates of seabird mortality, the US government and BP cooperatively conducted a series of natural resource damage assessment (NRDA) studies; results were made publicly available in August 2014 (GSD 2014). In many cases, parameters estimated from these data sets differ markedly from those used by Haney et al. For example, Haney et al. (2014b) estimate that only $\sim 6 \%$ of carcasses drifted ashore during the DHOS (i.e. the transport probability to shorelines was reported as 0.057). This estimate was developed without the benefit of GoM-specific carcass drift data collected in 2011, which

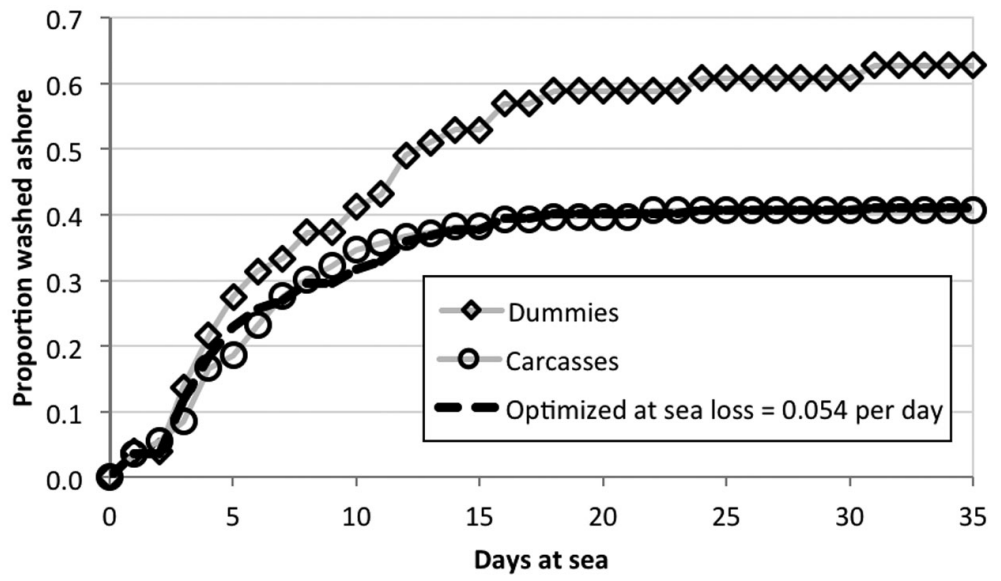

Fig. 1. Cumulative proportion of carcasses and dummies that drifted to shore in 2011 as a function of time spent at sea. A daily at-sea loss rate of $0.054 \mathrm{~d}^{-1}$ was estimated through a nonlinear least squares fitting routine assuming a standard exponential decay function are currently undergoing cooperative quality assurance review (GSD 2014).

From 16 July to 19 August 2011, 199 radio-tagged carcasses were deployed in coastal waters across the northern GoM (carcasses deployed farther offshore near the wellhead were excluded). The carcasses were released in areas that contained the highest densities of birds potentially impacted during the DHOS. Of the 199 carcasses deployed, 81 were tracked into nearshore environments (i.e. not open water) with some portion of the carcass intact (81/199 $=0.41$, Fig. 1). In the same study, 51 radio-tagged dummies were deployed (plastic water bottles encased in neoprene designed to float like carcasses, but not otherwise subject to sinking or scavenging), 32 of which were tracked into nearshore environments $(32 / 51=0.63$, Fig. 1$)$. Based on the additional loss of carcasses relative to dummies we estimate an

at-sea loss rate of $0.054 \mathrm{~d}^{-1}$ (implying that $50 \%$ of the carcasses were lost due to sinking or scavenging over a $\sim 13 \mathrm{~d}$ period, Fig. 1). This rate is similar to the findings reported by Ford et al. (1996) from carcass drift studies conducted in Prince William Sound (15 to $20 \mathrm{~d}$ ) and the Gulf of Alaska ( 7 to $18 \mathrm{~d}$ ), and is 18 times lower than the estimate of $1.0 \mathrm{~d}^{-1}$ used by Haney et al., whose value implies that more than half of the carcasses are lost during the first day at sea and that $>98 \%$ of the carcasses are lost after $4 \mathrm{~d}$.

Using the analytical framework developed by Haney et al. (2014b, their Supplement Table S4) to characterize the drift of carcasses during the DHOS and substituting their at-sea loss rate with the rate based on GoM-specific data yields an estimate for the transport probability to shorelines of $0.769,13$ times greater

Table 1. Computation of oiled seabird carcass transport probability to shorelines along the northern Gulf of Mexico during the Deepwater Horizon oil spill. Data in Columns 1, 2, 3, and 4 are from Supplement Table S4 of Haney et al. (2014b), with 2 columns added (2a and 4a). See the Supplement in Haney et al. (2014b) for details

\begin{tabular}{|c|c|c|c|c|c|}
\hline $\begin{array}{l}(1) \\
\text { Distance } \\
\text { from shoreline, } \\
z(\mathrm{~km})\end{array}$ & $\begin{array}{c}(2) \\
\text { Haney et al. } \\
\exp -[(1.00 \mathrm{z}) / \\
\left.\left(4.1 \mathrm{~km} \mathrm{~d}^{-1}\right)\right]\end{array}$ & $\begin{array}{c}(2 \mathrm{a}) \\
\text { Gulf Science } \\
\exp -[(0.054 \mathrm{z}) / \\
\left.\left(4.1 \mathrm{~km} \mathrm{~d}^{-1}\right)\right]\end{array}$ & $\begin{array}{c}\text { (3) } \\
\text { Initial carcass } \\
\text { distribution } \\
\text { (from Table S1 in } \\
\text { Haney et al. 2014b) }\end{array}$ & $\begin{array}{c}(4) \\
\text { Haney et al. } \\
\text { probability of } \\
\text { shoreline depo- } \\
\text { sition }(2) \times(3)\end{array}$ & $\begin{array}{c}(4 \mathrm{a}) \\
\text { Gulf Science } \\
\text { probability of } \\
\text { shoreline depo- } \\
\text { sition }(2 \mathrm{a}) \times(3)\end{array}$ \\
\hline $0-5$ & 0.542 & 0.968 & 0.056 & 0.030 & 0.054 \\
\hline $5-10$ & 0.160 & 0.906 & 0.102 & 0.016 & 0.092 \\
\hline $10-15$ & 0.047 & 0.848 & 0.143 & 0.007 & 0.121 \\
\hline $15-20$ & 0.014 & 0.794 & 0.175 & 0.002 & 0.139 \\
\hline $20-25$ & 0.004 & 0.744 & 0.182 & 0.001 & 0.135 \\
\hline $25-30$ & 0.001 & 0.696 & 0.167 & 0 & 0.116 \\
\hline $30-35$ & 0 & 0.652 & 0.125 & 0 & 0.081 \\
\hline $35-40$ & 0 & 0.610 & 0.051 & 0 & 0.031 \\
\hline Total & & & 1.000 & 0.057 & 0.769 \\
\hline
\end{tabular}


than the value used by Haney et al. (Table 1). In other words, while Haney et al. (2014b) estimate that only $\sim 6 \%$ of carcasses drifted ashore, GOM-specific data support an estimate of $\sim 77 \%$. This reduces Haney et al.'s coastal seabird mortality estimates by more than an order of magnitude.

Spatial extent of the spill

Haney et al. (2014a,b) used satellite-derived estimates of average daily oil slick size as parameters in the exposure probability models, and daily composites were used to estimate initial distributions of oiled birds in the carcass model. Areal estimates of the spill are subject to substantial uncertainty: on 25 August 2010, the National Oceanic and Atmospheric Administration (NOAA) discontinued production of the Experimental Marine Pollution Surveillance Daily Composite Products (EMPS-DCP) used by Haney et al., and the products have not undergone any retrospective quality assurance checks. NOAA's original disclamer states, 'The Oil Analysis Program is a new program producing experimental products for the NOAA Satellite Analysis Branch and should be used with caution. Our products are not fully operational, not supported $24 \times 7$ and have not been vetted through the usual quality assurance process' (www.ssd.noaa. gov/PS/MPS/about_orig.html; accessed 15 April 2015, emphasis added). Therefore, these data products render questionable support to the analyses conducted by Haney et al.

In the probabilistic avian mortality models, an under- or overestimation of oil slick size leads to a concomitant under- or overestimate of the number of bird deaths. While Haney et al. assert that satellitederived estimates of oil extent are likely underestimates, independent studies and data highlighted in their manuscript suggest otherwise. For example, Fig. 1 of Haney et al. (2014a) presents the total duration and extent of surface oil slick derived from the Textural Classifier Neural Network Algorithm (TCNNA) developed for synthetic aperture radar data. The TCNNA-derived products are not referred to elsewhere in Haney et al. (2014a) and were developed independently of NOAA's EMPS-DCP. Despite using TCNNA-derived products to visually characterize the duration and extent of the DHOS, Haney et al. (2014a) provide no information that would allow the reader to assess the internal consistency (or lack thereof) between TCNNA-derived products and NOAA's EMPS-DCP. Using TCNNA-derived products, Garcia-Pineda et al. (2013a) estimated the total average daily oil slick size as $10750 \mathrm{~km}^{2}$, a value $43.4 \%$ lower than the EMPS-DCP-derived value of $19000 \mathrm{~km}^{2}$ used by Haney et al. (2014a, their Supplement Table S2).

\section{Oiling and mortality}

Haney et al. $(2014 \mathrm{a}, \mathrm{b})$ suggest that $33 \%$ of offshore birds and $40 \%$ of coastal birds died after encountering the oil slick, based on the number of birds recovered by survey teams during the DHOS and on literature values derived from Camphuysen \& Heubeck (2001). As we are unable to determine how the estimates of proportionate mortality (i.e. 22 to $89 \%$ with a median of $61 \%$ for marine birds with aerial foraging styles) were developed from the data in Camphuysen \& Heubeck (2001), we ask Haney et al. to provide a more complete explanation.

Haney et al.'s mortality estimates from the exposure probability models do not account for spatial variability in surface oil concentrations. NOAA's EMPSDCP do not distinguish between areas of thick oil and areas of sheen, whereas bird species differ in their sensitivity to degree of oiling (NOAA 1996). Clark et al. (2010) used airborne- and satellite-derived information to estimate that on 17 May 2010, the area of non-contiguous thick oil was $19 \%$ of the total slick area. Garcia-Pineda et al. (2013b) evaluated 2 different satellite data sets for 10 May 2010 and estimated that thick oil made up 53 to $56 \%$ of the total oiled area. Therefore, spatial variability in surface oil concentrations needs to be considered when determining exposure, degree of oiling, and mortality of seabirds in the models developed by Haney et al.

\section{Christmas Bird Count}

Haney et al. (2014b) used the 2009-2012 ${ }^{1}$ National Audubon Society (NAS) Christmas Bird Count (CBC) data from stations located in Florida, Alabama, Mississippi, Louisiana, and Texas (NAS 2010, Fig. 2a) to corroborate results of their predictive models that the DHOS reduced laughing gull Leucophaeus atricilla populations in the northern GoM by approximately

\footnotetext{
${ }^{1}$ Haney et al. (2014b) state that they evaluated the CBC data between 2010 and 2013, but their statistical analysis concerns data obtained between 2009 and 2012 (i.e. the 110th-113th CBCs) according to the NAS terminology and database. The CBC data referred to as 'winter 2010' by Haney et al. (2014b) were collected between 14 December 2009 and 5 January 2010
} 


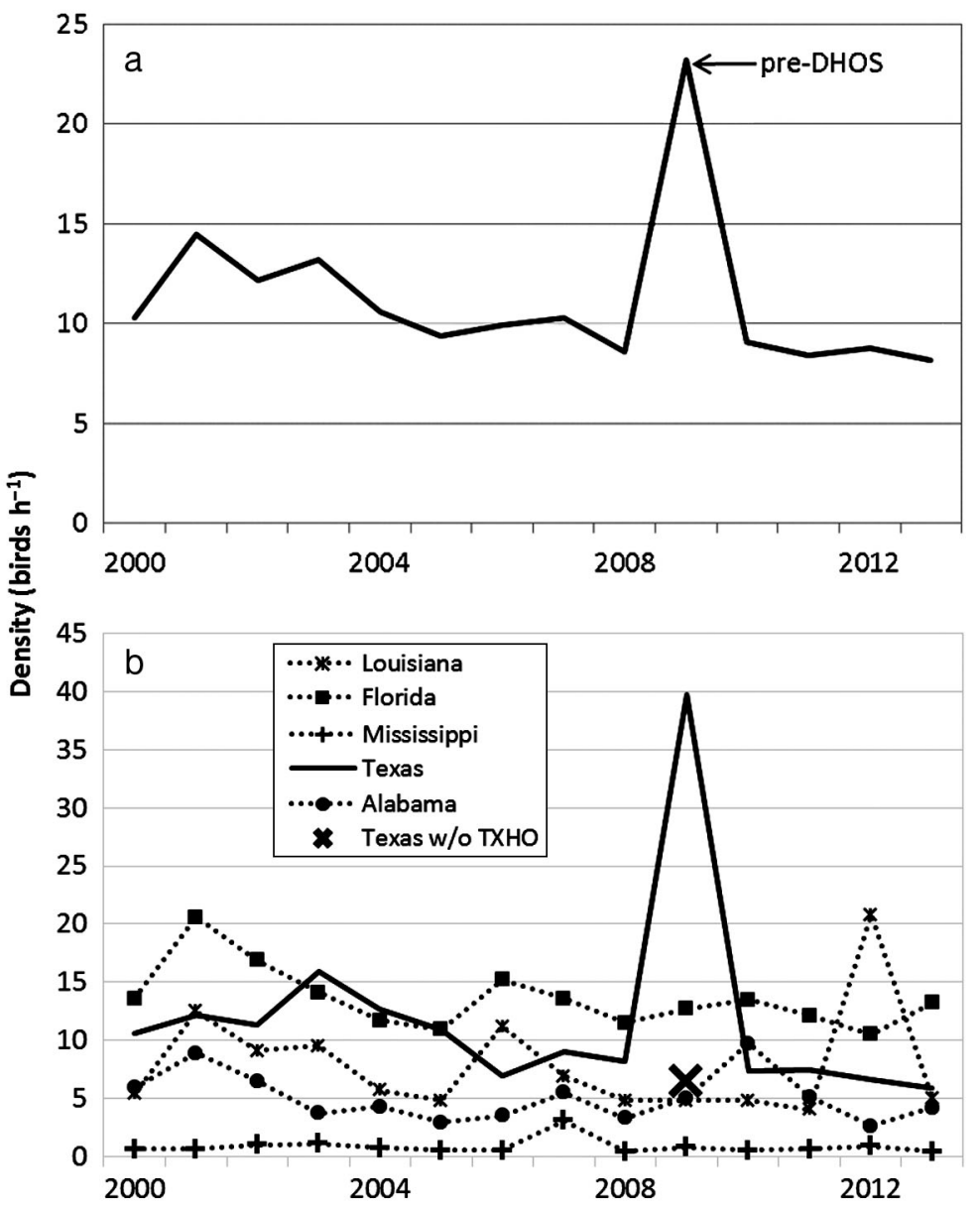

Fig. 2. Laughing gull densities estimated from National Audubon Society Christmas Bird Counts from (a) 5 Gulf states combined and (b) from Louisiana, Mississippi, Alabama, Florida, and Texas between 2000 and 2013; 'X' denotes the 2009 Texas value when the outlier at Station TXHO is removed from the data set

$32 \%$. They stated that ' $\mathrm{CBC}$ data reveal that after the Deepwater Horizon incident, laughing gulls in the Gulf region declined by 61 to $64 \%$ between winter 2010 and winters 2011, 2012, and 2013' (Haney et al. 2014 b, p. 249), and concluded that 'declines in laughing gulls were confirmed by $\sim 60 \%$ reductions in National Audubon Society Christmas Bird Count data for 2010-2013 along the Gulf coast' (Haney et al. 2014b, p. 239). Although the statistical methods used by Haney et al. (2014b) are not detailed, we attempted to reconstruct their $\mathrm{CBC}$ analysis.

The 2009 pre-spill data point of 23.2 birds counted per hour (birds $\mathrm{h}^{-1}$, Fig. 2a) is an outlier compared to data for 2000 to 2008 (8.6 to 14.5 birds h ${ }^{-1}$ ); identified using a 1 -sided Grubbs' test $(\alpha=0.05)$. Therefore, the combined 5-state value from 2009 is not representative of the longer-term patterns in laughing gull densities and should not be used as the sole basis of comparison with the post-spill densities. Haney et al. (2014b) apparently used the 2009 outlier value to calculate a laughing gull mortality of 61 to $64 \%$ following the spill.

Furthermore, the 2009 Texas value of nearly 40 birds $^{-1}$ (Fig. 2b) is substantially greater than any other value from Texas or the other GoM states over the 10 yr period preceding the DHOS. CBC data from individual locations in Texas in 2009 reveal an unusually high count of laughing gulls $(\mathrm{n}=$ $251000 ; 3260$ birds $\mathrm{h}^{-1}$ ) at Station TXHO near Houston on 26 December 2009. These results are flagged with ' $\mathrm{HC}$ ' in the NAS database, i.e. they represent an 'unusually high count' (http://birds.audubon.org/sites/ default/files/documents/ab_111_editorial_ codes.pdf; accessed 15 April 2015) and are considerably higher than the other values recorded from 2000 to 2013 for Station TXHO, which ranged from 8 to 266 birds $\mathrm{h}^{-1}$. Because the Station TXHO outlier was also incorporated into the 5 -state combined data set used by Haney et al. it biased the 2009 pre-spill data point (Fig 2a) that was used to corroborate their model results.

Fig. $2 \mathrm{~b}$ shows that when Station TXHO is removed from the 2009 Texas data set, the statewide average value is reduced to 6.4 birds $\mathrm{h}^{-1}$, which is consistent with values before and after the DHOS. Fig. 2b also shows that there were no obvious effects of the DHOS on laughing gull densities in Louisiana, Mississippi, Alabama, or Florida. A similar analysis of $\mathrm{CBC}$ data for northern gannet Morus bassanus, brown pelican Pelecanus occidentalis, and royal tern Thalasseus maximus-other coastal species highlighted by Haney et al. as potentially experiencing population-level repercussions also showed no obvious effects of the DHOS, although we recognize, as did Haney et al. (2014b), that the fewer observations of these species could limit the usefulness of $\mathrm{CBC}$ data in these cases.

\section{Recommendations}

A reliable and credible estimate of seabird mortality after the DHOS requires detailed evaluation of assumptions, modeling methods, and parameter estimates - all of which can be refined by incorporating 
appropriate GoM- and spill-specific information. We used GoM-specific information to show that the transport probability to shorelines used by Haney et al. (2014b) results in an order of magnitude overestimate of coastal seabird mortality and that the available NRDA data do not support their current estimate for this parameter. Also, the variability introduced by using different satellite-derived data to quantify the area and thickness of oil patches needs to be examined more closely, as do the proportion of oiled birds that die, and species-specific sensitivity to oiling. Finally, pre-spill density estimates for laughing gulls need to exclude the anomalously high bird count at CBC Station TXHO in 2009 if these data are to be used to corroborate estimates of avian mortality.

Acknowledgements. The authors declare the following competing financial interest(s): this work was supported by BP Exploration and Production Inc. The views expressed are solely those of the authors.

\section{LITERATURE CITED}

Camphuysen CJ, Heubeck M (2001) Marine oil pollution and beached bird surveys: the development of a sensitive monitoring instrument. Environ Pollut 112:443-461

Clark RN, Swayze GA, Leifer I, Livo EK, and others (2010) A method for quantitative mapping of thick oil spills using imaging spectroscopy. Open-file Rep (US Geol Surv) 2010. http://pubs.usgs.gov/of/2010/1167

Ford RG, Bonnell ML, Varoujean DH, Page GW and others (1996) Total direct mortality of seabirds from the Exxon Valdez oil spill. Am Fish Soc Symp 18:684-711

French McCay D, Rowe JJ (2004) Evaluation of bird impacts

Editorial responsibility: Matthias Seaman, Oldendorf/Luhe, Germany; Christine Paetzold, Oldendorf/Luhe, Germany in historical oil spill cases using SIMAP oil spill model. In: Proc 27th Arctic and Marine Oil Spill Program (AMOP) Technical Seminar. Emergencies Science Division, Environment Canada, Ottawa, p 421-452

> Garcia-Pineda O, MacDonald IR, Li X, Jackson CR, Pichel WG (2013a) Oil spill mapping and measurement in the Gulf of Mexico with Textural Classifier Neural Network Algorithm (TCNNA). IEEE J Sel Topics Appl Earth Observ Remote Sens 6:2517-2525

- Garcia-Pineda O, MacDonald I, Hu C, Svejkovsky J, Hess M, Dukhovskoy D, Morey SL (2013b) Detection of floating oil anomalies from the Deepwater Horizon oil spill with synthetic aperture radar. Oceanography (Wash DC) 26:124-137

GSD (Gulf Science Data) (2014) Data inputs for beached bird assessment data file. http://gulfsciencedata.bp. com/, directory: Birds; subdirectory: Data Inputs for Beached Bird Assessment; filename: BirdsBeachedBirdData_B-09v01-01.xlsx (zipped). Last modified August 2014

Haney CJ, Geiger HJ, Short JW (2014a) Bird mortality from the Deepwater Horizon oil spill. I. Exposure probability in the offshore Gulf of Mexico. Mar Ecol Prog Ser 513: 225-237

> Haney CJ, Geiger HJ, Short JW (2014b) Bird mortality from the Deepwater Horizon oil spill. II. Carcass sampling and exposure probability in the coastal Gulf of Mexico. Mar Ecol Prog Ser 513:239-252

NAS (National Audubon Society) (2010) The Christmas bird count historical results. Available at www.christmasbirdcount.org (accessed 12 Dec 2014)

NOAA (National Oceanic and Atmospheric Administration) (1996) Injury assessment: guidance document for Natural Resource Damage Assessment under Oil Pollution Act of 1990, Appendix D. NOAA, Silver Springs, MD. www.darrp.noaa.gov/library/pdf/iad.pdf (accessed 28 Apr 2015)

Paine RT, Ruesink JL, Sun A, Soulanille EL and others (1996) Trouble on oiled waters: lessons from the Exxon Valdez oil spill. Annu Rev Ecol Syst 27:197-235

Submitted: April 16, 2015; Accepted: August 7, 2015

Proofs received from author(s): August 18, 2015 